\title{
Yetiştirici Koşullarındaki Kıvırcık Koyunlarında Meme Özelliklerinin Belirlenmesi
}

\author{
Hilal AKGÜN ${ }^{1}$, Mehmet KOYUNCU ${ }^{2}$ \\ ${ }^{1}$ Ziraat Yüksek Mühendis, Balıkesir, ${ }^{2}$ Bursa Uludağ Üniversitesi Ziraat Fakültesi Zootekni Bölümü, Bursa \\ ${ }^{1}$ https://orcid.org/0000-0001-5563-9205, ${ }^{2}$ https://orcid.org/0000-0003-0379-7492 \\ $\varpi:$ koyuncu@uludag.edu.tr
}

\begin{abstract}
ÖZET
$\mathrm{Bu}$ araştırma ile yetiştirici koşullarındaki Kıvırcık koyunlarında meme özellikleri, linear meme puanları ve bu özelliklerin birbirleri ile ilişkisini ortaya konmuştur. Araştırmada yaşları 3-5 arasında değişen toplam 38 baş Kıvırcık koyunu kullanılmıştır. Meme özellikleri olarak meme çevresi, meme yüksekliği, meme uzunluğu, iki meme arası uzaklık, meme başı genişliği ve meme başı uzunluğu değerleri sirasiyla; $37.2 \mathrm{~cm}, 17.1 \mathrm{~cm}, 22.8 \mathrm{~cm}, 16.5 \mathrm{~cm}, 18.8 \mathrm{~mm}$ ve $27.3 \mathrm{~mm}$ olarak bulunmuştur. Linear meme özellikleri olarak meme başı yerleşimi, meme derinliği, ayrılma derecesi ve meme bağlantı derecesi ortalamaları sırasıyla; $4.6,8.0,3.4$ ve 6.9 olarak puanlanmıştır. Değerlendirmeye alınan meme özellikleri üzerine kontrol dönemleri ve koyunların canlı ağırlığının etkisi önemli $(\mathrm{P}<0.05, \mathrm{P}<0.01)$, doğum tipinin etkisi önemsiz bulunmuştur. Linear meme özelliklerine koyunların canlı ağırlığı ve doğum tipinin etkisi önemsiz bulunmuştur.
\end{abstract}

\section{Determination of Udder Characteristics in Kıvircı Sheep under the Breeder Conditions}

\section{ABSTRACT}

This study was conducted to determine udder characteristics, linear udder scores and the relationship of these characteristics with each other of Kivircik sheep in breeder conditions. A total of 38 heads of Kivircik ewes were used in the study. Udder morphology characteristics of the traits including udder circumference, udder height, udder length, teat distance, teat width and teat length values were measured as $37.2 \mathrm{~cm}, 17.1 \mathrm{~cm}, 22.8 \mathrm{~cm}, 16.5 \mathrm{~cm}, 18.8 \mathrm{~mm}$ and $27.3 \mathrm{~mm}$ respectively. Linear scores including teat placement, udder depth, degree of separation and degree of suspension of the udder were scored as 4.6, 8.0, 3.4 and 6.9, respectively. The effect of the control periods and live weight of the sheep were significant on the udder characteristics $(\mathrm{P}<0.05, \mathrm{P}<0.01)$, and the effect of the type of birth was insignificant. The effects of the live weight and type of birth on the linear scores udder characteristics were insignificant.
Araştırma Makalesi

Makale Tarihçesi

Geliş Tarihi : 17.09 .2020

Kabul Tarihi : 23.11 .2020

Anahtar Kelimeler

Koyun

Kıvırcık

Meme Özellikleri

Linear Meme Puanı

Atıf İçin : Akgün H, Koyuncu M 2021. Yetiştirici Koşullarındaki Kıvırcık Koyunlarında Meme Özelliklerinin Belirlenmesi. KSÜ Tarım ve Doğa Derg 24 (4): 904-913. DOI: 10.18016/ksutarimdoga.vi.796314.

To Cite : Akgün H, Koyuncu M 2021. Determination of Udder Characteristics in Kıvırcık Sheep Under the Breeder Conditions. KSU J. Agric Nat 24 (4): 904-913. DOI: 10.18016/ksutarimdoga.vi.796314.

\section{GİRIŞ}

Türkiye'de koyun yetiştiriciliğinin ağırlıklı olarak ekstansif koşullarda sürdürülmesi elde edilen sütün miktar ve kalitesine etki yapabilmektedir. Kaliteli bir süt için öncelikle koyunların sağlıklı bir memeye sahip olmalarının yanında sağım sonrası sütün maruz kaldığı çevresel koşullar da büyük önem taşımaktadır. Sağlıklı bir meme yapısı, süt üretimi ve kalitesinin yanında yavruların beslenmesi açısından önemlidir. Türkiye'de küçükbaş sağımının genellikle elle yapılıyor olması ve sağım sırasında sağım yapanların kendilerini hayvanın meme yapısına göre ayarlaması meme şeklini önemli bir hale getirmektedir. Diğer taraftan son yıllarda makine ile sağımın yaygınlaşması ile meme yapısı sağım performansını direkt olarak etkileyen bir özellik olarak da öne çıkmaktadır. Süt verimi yönünde ıslah edilen hayvanlarda memenin vücuda bağlantısını sağlayan meme merkez bağının kuvvetli olması ki bunun zayıf olduğu durumlarda sağımın ilerleyen dönemlerinde memelerde sarkmalar ortaya çıkmasına neden olabilmekte (Kumlu, 1999), ayrıca sarkık yapıdaki memelerde yaralanma ve çevresel patojenlere maruz 
kalma ve buna bağlı mastitis riski de artmaktadır (Uzmay ve ark., 2003).

Süt koyunları için süt verimi ve bileşimi ana seleksiyon hedefi olmakla birlikte, son ylllarda sağımın teknolojik yönleri, üretim kalitesi, fonksiyonel uzun ömürlülük ve hayvan refahı ile bağlantılı özellikler modern islah programlarında daha önemli hale gelmiştir. Makineli sağımın süt koyunculuğunda daha yaygın kullanılması ile birlikte, kolay ve birörnek bir sağım rutini sağlamak için yetiştiriciler ve bilim insanları tarafından memenin morfolojik ve fonksiyonel özelliklerine ilginin artmasını sağlamıştır. Koyun memesinin mekanik sağım için ideal morfolojisi Labousière (1988) tarafından tanımlanmıştır. Bir memenin yaralanmasına yol açmayacak şekilde makineli sağımının verimliliğini artırmak için, bazı meme morfolojisi özelliklerinin yeni seçim kriterleri olarak uygulanma olasılıkları temelinde sağılabilirlik ile bağlantılı olarak ele alınmaktadır. İspanya (De la Fuente ve ark., 1996; Serrano ve ark., 2002) ve Fransa'da (Marie-Etancelin ve ark. 2005) çeşitli süt koyunu ırklarında memenin nitelendirmesinde doğrusal puanlar kullanılmaktadır. Fernández ve ark., (1997), Serrano ve ark., (2002) ve Legarra ve Ugarte (2005), meme tipi özellikleri için orta düzeyde bir kalıtım derecesi elde ederlerken, bu yönde koyunlara uygulanacak bir seleksiyondan iyi yanıt alınabileceğini ortaya koymuşlardır.

Koyunlar farklı meme tiplerine sahiptirler (Epstein, 1985). Koyunların damızlık seçiminde meme tipinin süt verimine etkisi olduğu birçok araştırmacı tarafından ortaya konmuştur. Meme başlarının memede bulundukları yer ve meme genişliklerinin istenilenin dışında olması süt akışını ve sağımı zorlaştırabilmekte bu da sütte kalitenin bozulmasına neden olabilmektedir. Bu konudaki çalışmalar, süt koyunlarında süt veriminin meme ve meme başı özellikleriyle pozitif yönde ilişkili olduğunu göstermektedir (Izadifard ve Zamiri, 1997; Iniguez ve ark., 2009). Bununla birlikte Mavrogenis ve ark., (1989), süt üretim seviyeleri ile meme özellikleri arasında düşük bir korelasyon olduğunu belirtmiştir. Ayrıca meme yapısını genotip (Martinez ve ark., 2011), laktasyon sayısı (Gelasakis ve ark., 2012) ve süt verimi (Fernandez ve ark., 1995) gibi sağımı etkileyebilecek birçok faktör olduğu da unutulmamalıdır.

Linear (doğrusal) puanlama meme parametreleri, seleksiyonda dikkate alınan bir özellik olup, veri toplamayı basitleştirmekte büyük sürülerde meme özelliklerinin pratik olarak değerlendirilmesini sağlamaktadır. Linear meme özelliklerine göre skalada optimum seviyeyi geçebilen hayvanlar sürüde kalmakta, böylelikle sürü sürekli bir seleksiyona tabi tutulabilmektedir. Böylece, sütçü hayvan sürülerinde etkili ve kolay uygulanabilir bir islah programının uygulanabilme koşulları da yaratılmış olmaktadır (Trimberger ve ark., 1992; Prpić ve ark. 2012;
Makovický ve ark., 2013).

$\mathrm{Bu}$ çalışmanın amacı, yetiştirici koşullarındaki Kıvırcık ırkı koyunlarda meme ölçüleri, meme puanlama ve parametreleri ile bu özelliklerin birbirleriyle olan ilişkilerini araştırmaktır. Elde edilecek sonuçların özellikle meme tipleri bakımından yerli koyun ırkları ile yapılan sinırlı sayıdaki araştırmaya katkı sağlayacağı düşünülmektedir.

\section{MATERYAL ve METOD}

Araştırmada Balıkesir ili Balya ilçesinde bulunan özel bir koyunculuk işletmesinde, 3-4. laktasyon döneminde olan 38 baş Kıvırcık koyununun meme ölçüleri değerlendirilmiştir. İşletmedeki koyunculuk faaliyeti ağırlıklı olarak ekstansif yetiştirme şeklinde sürdürülmekte olup, ilkbahar ve yaz aylarında herhangi bir ek yemleme yapılmaksızın sadece meraya dayalı bir yetiştirme sistemi uygulanmaktadır. MartAğustos ayları arasında koyunlar ağıla sabah ve aksam sadece sağım için getirilmekte ve geriye kalan zamanda ise merada otlatılmaktadırlar. Eylül-Kasım aylarında ise koyunlar merada yaylmaya devam etmektedir. Aralık-Şubat ayları arasında gebeliğin son dönemi ve doğumun yaklaşmasından dolayı meraya ilave olarak koyunlara ek yemleme yapılmaktadır. Koyunların doğumları Ocak ayı sonunda başlayıp Şubat ayının sonuna kadar devam etmektedir.

Koyunların canlı ağırlık gibi sürekli varyasyon gösteren faktör kesikli hale getirilmiştir. Bu amaçla ana canlı ağırlığ belirlenmiş, ortalamanın altında kalan $(<54)$ ve ortalamanın üstünde olanlar $(\geq 54)$ olarak gruplandırılmıştır.

Meme ölçümleri koyunlar meradan gelip bir süre dinlendirildikten sonra akşam saatlerinde sağım öncesi yapılarak Mart-Temmuz ayları arası 14 gün aralıklar ile 9 kez alınmıştır (Şekil 1).

Koyunların meme tiplerinin belirlenmesine doğum yaptıktan sonraki dönem içinde doğrusal bir skala ile memenin morfolojik olarak değerlendirilmesi yapılmıştır. Bu işlem memelerin fotoğrafları çekilmek suretiyle bilgisayar ekranına aktarılarak uygulanmıştır. $\mathrm{Bu}$ değerlendirmede, koyun memelerinin morfolojik olarak belirlemek için birden dokuza kadar olan (1-9) bir skala kullanılmıştır (Şekil 2), (Casu ve ark., 2006).

Memenin morfolojik olarak değerlendirilmesinde dikkate alınan kriterler; Meme başı yerleşimi (MBY), Meme derinliği (MD), İki yarının ayrılma derecesi (AD) ve Meme bağlantı derecesi (MBD) dir. Bu değerlendirme, koyun memelerinin fotoğrafı çekilmek suretiyle, bilgisayar ekranindan puanlanmasina dayanmaktadır (Casu ve ark., 2006, Koyuncu ve Altınçekiç 2016). 


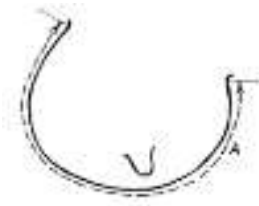

Meme uzunluğu

(Udder length)

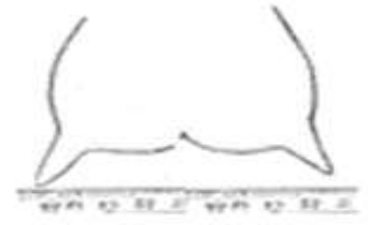

İki meme başı arası uzaklık (Teat distance)

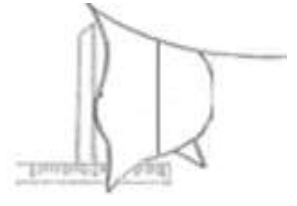

Meme yüksekliği (Udder height)

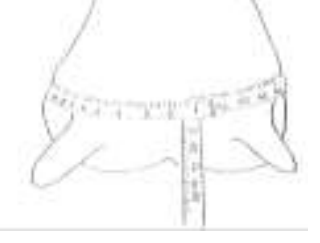

Meme çevresi (Udder circumference)

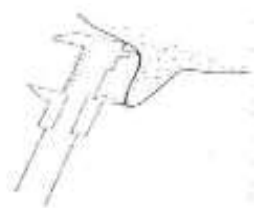

Meme başı uzunluğu (Teat length)

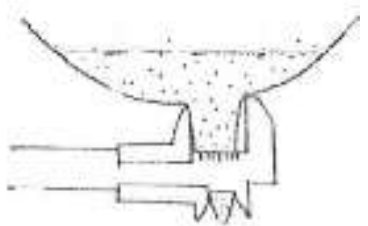

Meme başı genişliği (Teat width)

Şekil 1. Meme ölçülerine ait değerlendirme (Kızılay 1983)

Figure 1. Evaluation of udder size

Meme bașı yerleşimi-MBY

(Teat placement-TP)
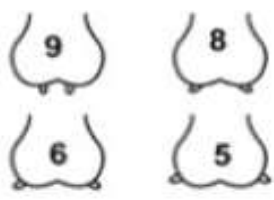

3

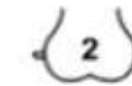

Ayrilma derecesi-AD

(Degree of separation-DSE)

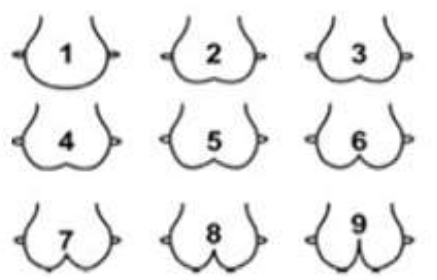

Meme derinliği-MD

(Udder depth-UD)

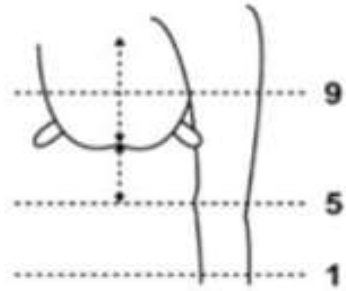

Meme bağlantı derecesi-MBD

(Degree of suspension-DSU)
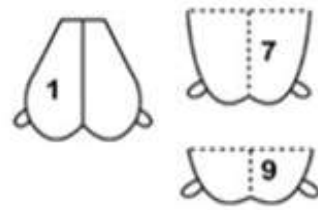

Şekil 2. Meme özelliklerine ait linear ölçüler (Casu ve ark. 2006)

Figure 2.Linear udder measurements

\section{İstatistik Analizler}

Elde edilen veriler Minitab 17.0 paket programı ile aşağıdaki matematik model kullanılarak değerlendirilmiştir (Minitab 2014). Gruplar arasındaki farklılıkların belirlemek için Tukey çoklu karşılaştırma testi uygulanmıştır.

$\mathrm{Y}_{\mathrm{ijkl}}=\mathrm{m}+\mathrm{ai}_{\mathrm{i}}+\mathrm{b}_{\mathrm{j}}+\mathrm{ck}_{\mathrm{k}}+\mathrm{e}_{\mathrm{ijk} \mathrm{k}}$

$\mathrm{Y}_{\mathrm{ijkl}}=\mathrm{i}$. dönemdeki $\mathrm{j}$. doğum tipindeki, k. canlı ağırlığındaki ölçülen değer

$\mathrm{m}$ = popülasyonun beklenen ortalamasını

$a_{i}=i$. dönemin etkisini $\left(d_{1}, d_{2}, d_{3}, d_{4}, d_{5}, d_{6}, d_{7}, d_{8}, d_{9}\right)$

$b_{j}=j$. doğum tipinin etkisini (tekiz, ikiz)

$c_{\mathrm{k}}=\mathrm{k}$. canlı ağırlığının etkisini $(<54, \geq 54)$ $\mathrm{e}_{\mathrm{ijkl}}=$ Ortalaması sıfir standart sapması $\sigma_{e}^{2}$ olan hata etkisini göstermektedir.

İnteraksiyonlar ilk önce modele dâhil edilmiştir ancak önemli bulunmadıkları için çıkarılmıştır.

\section{BULGULAR ve TARTIŞMA}

Meme özellikleri için tanımlayıcı değerler Çizelge 1'de verilmiştir. Meme özellikleri kapsamında meme çevresi (MÇ), meme yüksekliği (MY), meme uzunluğu (MU), iki meme arası uzaklık (IMAU), meme başı genişliği (MBG) ve meme başı uzunluğu (MBU) için bulunan ortalama değerler $37.2 \pm 0.27, \quad 17.1 \pm 0.12$, $22.8 \pm 0.16,16.5 \pm 0.08,18.8 \pm 0.21$ ve $27.3 \pm 0.31 \mathrm{~cm}$ olarak siralanmaktadir. 
Çizelge 1. Meme özellikleri için tanımlayıcı istatistikler

Table 1. Descriptive statistics for udder characteristics

\begin{tabular}{lllllll}
\hline Özellikler (Parameters) & $\mathrm{N}$ & $\bar{x} \pm S \bar{x}$ & SD & CV\% & Min. & Max. \\
\hline MÇ (UD) & 342 & $37.2 \pm 0.27$ & 4.92 & 22.0 & 13.23 & 49.0 \\
MY (UH) & 342 & $17.1 \pm 0.12$ & 2.26 & 10.0 & 13.23 & 32.0 \\
MU (UL) & 342 & $22.8 \pm 0.16$ & 2.99 & 13.0 & 13.14 & 32.0 \\
IMAU (TD) & 342 & $16.5 \pm 0.08$ & 1.51 & 10.0 & 9.13 & 20.0 \\
MBG (TW) & 342 & $18.8 \pm 0.21$ & 3.87 & 10.5 & 20.64 & 31.8 \\
MBU (TL) & 342 & $27.3 \pm 0.31$ & 5.65 & 1.61 & 20.75 & 45.3 \\
\hline
\end{tabular}

MÇ/UD: Meme çevresi/Udder circumference, MY/UH: Meme yüksekliği/Udder height, MU/UL: Meme uzunluğu/Udder length, IMAU/TD: İki meme başı arası uzaklık/Teat distance, MBG/TW: Meme başı genişliği/Teat width, MBU/TL: Meme başı uzunluğu/Teat length.

Kıvırcık koyunlarında meme özelliklerine ait değerlere kontrol dönemleri, canlı ağırlık ve doğum tipinin etkisi ve bu faktörlere ait en küçük kareler ortalamaları Çizelge 2'de verilmiştir. İyi ve sağlıklı olarak değerlendirilen bir meme; büyük hacimli ve karna doğru kavis yapan, meme başları belirgin, meme sarnıcına dokunulduğunda dokunun yumuşak ve elastik olduğu hissedilmeli, meme orta yükseklikte olmalı dize kadar inmemeli, meme bağ dokusu belirgin, meme başları orta uzunluk ve genişlikte olmalı, yere dik olarak uzanmalıdır. Bu kapsamda laktasyon süt verimi üzerine tüm meme özelliklerinin önemli düzeyde etkiye sahip olduğu ifade edilmektedir (Gallego ve ark. 1983; Fernandez ve ark. 1995).

Değerlendirilen meme özelliklerinden meme çevresi ortalama $37.2 \mathrm{~cm}$ bulunmuş olup, laktasyon döneminin etkisi önemlidir $(\mathrm{P}<0.01)$. Koyunların canlı ağırlık değeri sürü ortalamasından yüksek olanların $(38.3 \mathrm{~cm})$, düşük olanlardan $(35.7 \mathrm{~cm})$ meme çevresi daha yüksek olup aralarındaki farkın önemli olduğu saptanmıştır $(\mathrm{P}<0.01)$. İkiz doğuran koyunların tekiz doğuranlara göre meme çevresi yaklaşık $1 \mathrm{~cm}$ daha büyük bulunmuştur. Banchero ve ark. (2004), ikiz doğuran koyunlar tekiz doğuranlara göre daha büyük memelere sahip olduğunu belirtmiştir. Bunun nedeni çoklu fetüs taşıyan koyunların gebelik sırasında daha yüksek plasenta ağırlığına, daha yüksek serum progesteronuna ve daha fazla plasental laktojen hormonuna sahip olduğu şeklinde belirlenmiştir (Butler ve ark. 1981; Schoknecht ve ark. 1991). Sonuç olarak, meme bezleri gebelik ve doğum sırasında daha iyi gelişir. $\mathrm{Bu}$ da meme bezlerinin ikizler tarafından tekiz kuzulara göre daha sık emildiği anlamina gelebilir.

Koyuncu ve Altınçekiç (2011) meme çevresini Tahirova, Kıvırcık ve Karacabey Merinosu irkı koyunların sirasiyla 43.00, 35.82 ve $34.34 \mathrm{~cm}$; Sezenler ve ark. (2016) Bandırma koyununda ise bu değeri 45.9 $\mathrm{cm}$ olarak bulmuşlardır. $\mathrm{Bu}$ araştırmada farklı dönemlerde tekrarlanarak ölçümler alındığından, yapılan çalışmalarda ölçümlerin hangi dönemlerde alındığından hareket ile farklılıkların veya benzerliklerin olduğu görülmektedir.

Kıvırcık koyunlarında ortalama meme yüksekliği 17.1 $\mathrm{cm}$ bulunmuştur. Laktasyon dönemlerinin meme yüksekliğine etkisi önemli bulunmuştur $(\mathrm{P}<0.05)$. Canlı ağırlığın sürü ortalaması üzerinde olan koyunların meme çevresi daha yüksek olup aralarındaki farklılık önemlidir $(\mathrm{P}<0.01)$. Doğum tipinin meme çevresi üzerine etkisi ise önemsiz bulunmuştur. Kıvırcık koyunlarındaki bu sonuç, Doğan ve ark. (2013) Anadolu Merinosu koyunlarla buldukları $18.86 \mathrm{~cm}$ değerinden düşük olmakla beraber, Mundan ve Özbeyaz (2004) tarafindan Akkaraman, Kıvırcık x Akkaraman ve Sakız x Akkaraman koyunlarda sirasiyla; $14.64,13.29$ ve $15.98 \mathrm{~cm}$ olarak buldukları değerlerinden yüksek bulunmuştur.

Meme uzunluğu ortalama $22.8 \mathrm{~cm}$ olup, dönemlerinin meme uzunluğuna etkisi önemli bulunmuştur $(\mathrm{P}<0.01)$. Koyunların canlı ağırlık gruplarının da meme uzunluğuna etkisi önemli $(\mathrm{P}<0.01)$ olup, canlı ağırlığı ortalamadan yüksek olan koyunların meme çevresi değerleride yüksektir. Doğum tipinin meme uzunluğuna etkisi önemsizdir. Koyuncu ve Altınçekiç (2011) Tahirova, Kıvırcık ve Karacabey Merinosu ırkı koyunlarda sirasiyla $23.02,22.11$ ve $21.33 \mathrm{~cm}$ olarak buldukları meme uzunluğu değerleri araştırma sonuçları ile oldukça benzerdir. Meme uzunluğunun fazla olması istenen bir durum olmayı, meme uzunluğu ne kadar fazla olursa memede yaralanma veya enfeksiyon problemlerine yakalanma riski o kadar yüksek olabilmektedir.

İki meme başı arası uzaklık araştırmada ortalama $16.5 \mathrm{~cm}$ olup, dönemin iki meme arasındaki uzaklığa olan etkisi istatistiki olarak önemli bulunmuştur $(\mathrm{P}<0.01)$. Ele alınan özelliğe canlı ağırlığın etkisi önemli $(\mathrm{P}<0.01)$, doğum tipinin etkisi ise önemsiz bulunmuştur. Laktasyonun boyunca meme çevresi, meme uzunluğu ve iki meme başı arası uzaklık birbirlerine benzer bir seyir izlemiştir. Laktasyonun sonuna doğru süt verimi azaldığı için meme hacmi, meme çevresi ve buna bağlı olarak iki meme başı arası uzaklık azalmaktadır. 
Çizelge 2. Meme özelliklerini etkileyen faktörler

Table 2. Factors affecting udder characteristics

\begin{tabular}{|c|c|c|c|c|c|c|c|c|}
\hline & $\mathrm{N}$ & $\begin{array}{l}\text { Meme } \\
\text { çevresi,cm } \\
\text { (Udder } \\
\text { circumference) }\end{array}$ & $\begin{array}{l}\text { Meme } \\
\text { yüksekliği, cm } \\
\text { (Udder } \\
\text { height) }\end{array}$ & $\begin{array}{l}\text { Meme uzunluğu, } \\
\mathrm{cm} \text { (Udder length) }\end{array}$ & $\begin{array}{l}\text { İki meme başı arası } \\
\text { uzaklık, cm } \\
\text { (Teat distance) }\end{array}$ & $\begin{array}{l}\text { Meme başı } \\
\text { genişliği, mm } \\
\text { (Teat width) }\end{array}$ & $\begin{array}{l}\text { Meme } \\
\text { uzunluğu, mm } \\
\text { (Teat length) }\end{array}$ & başı \\
\hline $\mathrm{R}^{2}, \%$ & & 51.92 & 15.33 & 24.86 & 21.48 & 24.03 & 17.11 & \\
\hline $\begin{array}{l}\text { Önemlilik } \\
\text { (Significance) }\end{array}$ & & $* *$ & $*$ & $* *$ & $* *$ & $* *$ & $* *$ & \\
\hline $\begin{array}{l}\text { Dönemler } \\
\text { (Periods) }\end{array}$ & & $\bar{X} \pm S_{\bar{X}}$ & $\bar{X} \pm S_{\bar{X}}$ & $\bar{X} \pm S_{\bar{X}}$ & $\bar{X} \pm S_{\bar{X}}$ & $\bar{X} \pm S_{\bar{X}}$ & $\bar{X} \pm S_{\bar{X}}$ & \\
\hline D1 & 38 & $41.2 \pm 0.57 \mathrm{a}$ & $17.6 \pm 0.29^{a}$ & $24.5 \pm 0.49 \mathrm{a}$ & $17.7 \pm 0.21^{\mathrm{a}}$ & $19.3 \pm 0.60 \mathrm{ab}$ & $25.4 \pm 0.85$ cd & \\
\hline D2 & 38 & $41.7 \pm 0.52^{\mathrm{a}}$ & $17.6 \pm 0.37 \mathrm{a}$ & $24.1 \pm 0.44^{\mathrm{a}}$ & $17.4 \pm 0.24^{\mathrm{a}}$ & $20.9 \pm 0.68^{a}$ & $28.7 \pm 1.02 \mathrm{ab}$ & \\
\hline D3 & 38 & $40.7 \pm 0.47$ a & $16.5 \pm 0.23 \mathrm{ab}$ & $23.7 \pm 0.38 \mathrm{a}$ & $17.0 \pm 0.22 \mathrm{ab}$ & $20.7 \pm 0.44$ & $29.6 \pm 0.88$ & \\
\hline D4 & 38 & $37.6 \pm 0.57 \mathrm{~b}$ & $16.7 \pm 0.25^{\mathrm{ab}}$ & $23.0 \pm 0.41 \mathrm{abc}$ & $16.2 \pm 0.22 \mathrm{bc}$ & $19.2 \pm 0.70 \mathrm{ab}$ & $29.5 \pm 1.07 \mathrm{a}$ & \\
\hline D5 & 38 & $38.1 \pm 0.70^{b}$ & $17.6 \pm 0.28^{a}$ & $23.1 \pm 0.41 \mathrm{ab}$ & $16.3 \pm 0.20 \mathrm{bc}$ & $18.3 \pm 0.58 \mathrm{bc}$ & $27.8 \pm 0.82 \mathrm{abc}$ & \\
\hline D6 & 38 & $35.3 \pm 0.53^{c}$ & $17.4 \pm 0.47 \mathrm{a}$ & $22.1 \pm 0.54 \mathrm{bcd}$ & $15.7 \pm 0.21^{\mathrm{c}}$ & $19.0 \pm 0.53 \mathrm{ab}$ & $27.4 \pm 0.76 \mathrm{abc}$ & \\
\hline D7 & 38 & $33.0 \pm 0.60 \mathrm{~d}$ & $17.1 \pm 0,47 \mathrm{~b}$ & $21.5 \pm 0.46^{\mathrm{cd}}$ & $15.7 \pm 0,23^{\mathrm{c}}$ & $17.3 \pm 0.54^{\mathrm{c}}$ & $25.2 \pm 0.96^{\mathrm{d}}$ & \\
\hline D8 & 38 & $33.5 \pm 0.67 \mathrm{~cd}$ & $17.7 \pm 0.49 \mathrm{a}$ & $22.0 \pm 0.48 \mathrm{bcd}$ & $16,1 \pm 0.27 \mathrm{c}$ & $18.7 \pm 0.59 \mathrm{~b}$ & $26.8 \pm 0.92$ abcd & \\
\hline D9 & 38 & $33.3 \pm 0.67 \mathrm{~d}$ & $16.0 \pm 0.26 \mathrm{~b}$ & $21.0 \pm 0.46^{\mathrm{d}}$ & $16.3 \pm 0.19 \mathrm{bc}$ & $16.5 \pm 0.57 \mathrm{c}$ & $25.8 \pm 0.70 \mathrm{bcd}$ & \\
\hline $\begin{array}{l}\text { Canlı ağırlık } \\
\text { (Live weight) }\end{array}$ & & $* *$ & $* *$ & $* *$ & $* *$ & $* *$ & $* *$ & \\
\hline$<54$ & 14 & $35.7 \pm 0.33 \mathrm{~b}$ & $16.4 \pm 0.20^{\mathrm{b}}$ & $21.7 \pm 0.25^{b}$ & $16.0 \pm 0.13 \mathrm{~b}$ & $17.4 \pm 0.32 \mathrm{~b}$ & $25.2 \pm 0.49 \mathrm{~b}$ & \\
\hline$\geq 54$ & 24 & $38.3 \pm 0.24^{\mathrm{a}}$ & $17.8 \pm 0.15^{\mathrm{a}}$ & $23.7 \pm 0.18^{a}$ & $16.7 \pm 0.09 \mathrm{a}$ & $19.9 \pm 0.24^{\mathrm{a}}$ & $28.7 \pm 0.37$ a & \\
\hline $\begin{array}{l}\text { Doğum tipi } \\
\text { (Birth type) }\end{array}$ & & ÖD $-N S$ & ÖD $-N S$ & ÖD -NS & ÖD $-N S$ & ÖD $-N S$ & ÖD -NS & \\
\hline Tekiz (Single) & 27 & $36.6 \pm 0.22$ & $16.6 \pm 0.14$ & $22.3 \pm 0.17$ & $16.4 \pm 0.09$ & $18.2 \pm 0.22$ & $26.6 \pm 0.34$ & \\
\hline İkiz ( Twin) & 11 & $37.5 \pm 0.35$ & $17.5 \pm 0.22$ & $23.1 \pm 0.27$ & $16.4 \pm 0.14$ & $19.2 \pm 0.35$ & $27.3 \pm 0.53$ & \\
\hline Genel $($ Overall $)$ & 342 & $37.2 \pm 0.27$ & $17.1 \pm 0.12$ & $22.8 \pm 0.16$ & $16.5 \pm 0.08$ & $18.8 \pm 0.21$ & $27.3 \pm 0.31$ & \\
\hline
\end{tabular}

* $\mathrm{P}<0.05,{ }^{* *} \mathrm{P}<0.01$, ÖD: Önemli değil, NS: Non significant 
Ayadi ve ark. (2011) Sicilo-Sarde ırkı koyunlarla iki meme başı arası mesafeyi $7.5 \mathrm{~cm}$; Yardımcı ve Özbeyaz (2001) Akkaraman ve Sakız x Akkaraman melezi koyunlarda 15.88 ve $16.16 \mathrm{~cm}$ olarak buldukları değerler bu araştırma sonucundan düşüktür. İki meme başı arası mesafe laktasyon dönemindeki hayvanlar için önemlidir. $\mathrm{Bu}$ mesafenin istenilen değerlerin dışında olması özellikle sağım ve kuzuların emme dönemlerinde problemlere yol açabilmektedir.

Meme başı genişliği sürüde ortalama $18.8 \mathrm{~mm}$ bulunmuştur. Kontrol dönemlerinin meme başı genişliğine etkisi önemli bulunmuştur $(\mathrm{P}<0.01)$. Meme başı genişliği kontrolün başladığı ilk dönemlerde 19-20 $\mathrm{mm}$ civarında bulunurken, sonunda $16.5 \mathrm{~mm}$ 'ye kadar düşmüştür. Koyunların canlı ağırlık değeri de meme başı genişliği üzerine etkisi önemli olup $(\mathrm{P}<0.01)$, iki grup arasındaki farklılık $2.5 \mathrm{~cm}$ ' ye ulaşmaktadır. Doğum tipi açısından ikiz doğuranların tekizlerden 1 $\mathrm{cm}$ daha geniş bir meme başı değerine sahip olmasına karşıllk bu fark önemsiz bulunmuştur. Legaz ve ark. (2011) Assaf koyunlarında meme başı genişliğini 1.74 $\mathrm{cm}$, Emediato ve ark. (2008) Bergamasca koyunlarında $2.28 \mathrm{~cm}$; Özyürek ve ark. (2016) Morkaraman, Tuj ve İvesi koyunlarda surasiyla $2.27,2.30$ ve $2.78 \mathrm{~cm}$ olarak belirlenmiştir. Meme başı genişliği süt verimi yönünde koyunların damızlık seçiminde önemli bir kriter olmanın yanında, meme başının dar veya geniş olması kuzularda emme sorunları yaratabilmektedir.

Meme başı uzunluğu koyunlarda ortalama $27.3 \mathrm{~mm}$ bulunmuştur. Farklı kontrol dönemlerinin meme başı uzunluğuna etkisi önemlidir $(\mathrm{P}<0.01)$. Yüksek canlı ağırlık grubundaki koyunların meme başı uzunluğu düşük canlı ağırlık grubundan yaklaşık $3.5 \mathrm{~mm}$ daha yüksek olup, bulunan farklılık önemlidir $(\mathrm{P}<0.01)$. İkiz doğuran koyunların meme başı uzunluğu tek doğuranlarda çok az bir farklılık göstermiş olmakla birlikte doğum tipinin etkisi önemsiz bulunmuştur.

Özyürek ve ark. (2016)'ın Morkaraman, Tuj ve İvesi ırkı koyunlarda meme başı uzunlukları sırasıyla; 2.63, 2.59 ve $2.43 \mathrm{~cm}$; Thomas ve ark. (2000) \%75 Doğu Friz, Doğu Friz ve Lacaune irkı koyunlarda sirasiyla; 2.7, 2.9 ve $2.5 \mathrm{~cm}$ olarak bulunmuştur. Meme başlarının çok uzun ya da kısa olması istenmeyen bir durumdur. Çünkü meme başları uzun olduğunda meme yere yakın olacağından enfeksiyon kapma riski yüksek olmanın yanında, meme başı çok kısa olduğunda ise kuzuların emmesi güç olduğu gibi sağım esnasında zorluklar yaşanabilmektedir.

Linear meme özellikleri, hayvanların sütçülük özelliklerini belirli bir puanlama esasına dayandırarak sütçü hayvanların seçilmesinde kolaylık sağlaması bakımından çok önemlidir. Linear meme özelliklerine göre değerlendirme yapılarak seleksiyon ile genetik ilerlemenin çok daha güvenli bir şekilde yapılması mümkün olmaktadır (Trimberger ve ark. 1992). Koyunlarda linear meme özelliklerin tanımlanması, ıslah ve işletmenin verimliliği açısından da önemlidir. Aynı zamanda linear meme özelliklerinin değerlendirilmesi, koyunculuk işletmelerinin verimliliğini doğrudan ilgilendiren bir öneme sahiptir (Koyuncu ve Altınçekiç 2011). Kıvırcık koyunlarında linear meme özellikleri için tanımlayıcı istatistikler Çizelge 3'de verilmiştir.

Linear meme özellikleri (meme başı yerleşimi, meme derinliği, ayrılma derecesi, meme başı derinliği) ile koyunların canlı ağırlıkları, kuzulama tipleri ve canlı ağırlık x doğum tipi değişkenleri arasındaki varyans analizi Çizelge 4'te verilmiştir.

Sadeghi ve ark. (2014) Ghezel, Ghezel x Arkhar Merinos ve Moghani x Arkhar Merinos irkı koyunlarla yapılan meme başı puanlaması sırasıyla; $4.49,5.40$ ve 4.90, Şeker ve ark. (2000) İvesi ve Ost-Friz x İvesi melezlerinde sirasiyla; 4.56 ve 6.10 ; Koyuncu ve Altınçekiç (2011) Tahirova, Kıvırcık ve Karacabey Merinosu koyunlarında 4.36, 5.06, 5.19 olarak buldukları değerler çalışma sonuçları ile benzerlik göstermektedir. Koyunlarda meme başlarının yerleşimi emzirme ve sağım süresi açısından büyük bir öneme sahiptir. Doğum döneminde kuzuların doğru pozisyonda emmesi sütten yeterli bir şekilde faydalanması gerekmektedir. Meme başları istenilen konumda olmazsa emme sorunları meydana gelebilmektedir. $\mathrm{Bu}$ özelliğe yönelik uygulanacak seleksiyon çalışmalarında, meme başlarının konumunu dikkate alan ideal bir puanlama ile sonraki generasyonlarda istenilen meme yapisına sahip koyunların elde edilebilmesi ile sürüde iyileştirme yapılabilir.

Çizelge 3. Linear meme ölçüleri için tanımlayıcı istatistikler

Table 3. Descriptive statistics for linear udder sizes

\begin{tabular}{lllllll}
\hline Özellikler (Parameters) & $\mathrm{N}$ & $\bar{x} \pm S \bar{x}$ & $\mathrm{SD}$ & CV\% & Min. & Max. \\
\hline MBY & 38 & $4.58 \pm 0.21$ & 1.31 & 28.60 & 1 & 7 \\
MD & 38 & $7.95 \pm 0.29$ & 1.79 & 22.52 & 5 & 9 \\
AD & 38 & $3.42 \pm 0.24$ & 1.46 & 42.69 & 1 & 6 \\
MBD & 38 & $6.90 \pm 0.48$ & 2.98 & 43.19 & 1 & 9 \\
\hline
\end{tabular}

MBY/TP. Meme başı yerleşimi/Teat placement, MD/UD: Meme derinliği/Udder depth, $\mathrm{AD} / D S E$. İki yarının ayrılma derecesi/Degree of seperation, MBD/DSU: Meme bağlantı derecesi/Degree of suspension 
Çizelge 4. Linear meme özelliklerini etkileyen faktörler

Table 4. Factors affecting linear udder characteristics

\begin{tabular}{lllllc} 
& $\mathrm{N}$ & $\begin{array}{l}\text { Meme başı yerleşimi } \\
\text { (Teat placement) }\end{array}$ & $\begin{array}{l}\text { Meme derinliği } \\
\text { (Udder depth) }\end{array}$ & $\begin{array}{l}\text { Ayrlma derecesi } \\
\text { (Deg. of seperation) }\end{array}$ & $\begin{array}{l}\text { Meme bağlantı derecesi } \\
\text { (Deg. of suspension) }\end{array}$ \\
\hline $\mathrm{R}^{2}, \%$ & 4.54 & 2.58 & 4.02 & 3.67 \\
\hline Canlı ağırlık & & & & \\
(Live weight) & & ÖD $-N S$ & ÖD $-N S$ & ÖD $-N S$ & ÖD $-N S$ \\
$<54$ & 14 & $4.8 \pm 0.43$ & $8.0 \pm 0.60$ & $3.4 \pm 0.49$ & $6.7 \pm 0.99$ \\
$\geq 54$ & 24 & $4.3 \pm 0.29$ & $7.8 \pm 0.40$ & $3.3 \pm 0.32$ & $7.1 \pm 0.66$ \\
\hline Doğum tipi & & & & \\
(Birth type) & ÖD $-N S$ & ÖD $-N S$ & ÖD $-N S$ & ÖD $-N S$ \\
Tekiz (Single) & 27 & $4.7 \pm 0.26$ & $8.1 \pm 0.36$ & $3.5 \pm 0.29$ & $6.8 \pm 0.60$ \\
İkiz (Twin) & 11 & $4.4 \pm 0.45$ & $7.6 \pm 0.62$ & $3.3 \pm 0.51$ & $7.0 \pm 1.03$ \\
\hline Genel (Overall) & 38 & $4.6 \pm 0.21$ & $8.0 \pm 0.29$ & $3.4 \pm 0.24$ & $6.9 \pm 0.48$ \\
\hline OD: On
\end{tabular}

ÖD: Önemli değil, NS: Non significant

Koyunlardan elde edilen meme derinliği puanı ortalama 8.0 olarak bulunmuştur. Meme derinliğinin arka diz eklemine yakın ve ortalama 6-7 puan arasında olması ideal kabul edilmektedir (Koyuncu ve Altınçekiç 2016). Casu ve ark. (2010) Sarda x Lacaune melezi koyunlarda bu özellik için değeri 6.63 bulmuşlar; Margetín ve ark. (2012) 381 baş koyunun linear meme derinliği 5.04 olarak tespit etmişlerdir. Meme derinliği Tahirova, Kıvırcık ve Karacabey Merinosu koyunlarinda sirasiyla; 6.77, 6.60 ve 6.49 bulunmuştur (Koyuncu ve Altınçekiç 2011). Bu araştırmada meme derinliği için bulunan değer diğer çalışmalara göre yüksek ve ideal olarak belirtilen değerin dişındadır.

Koyunların iki meme başının bağlanma noktaları arasındaki ayrılma derecesi ortalama 3.4 olarak belirlenmiştir. Salaris ve ark. (2014) Sardunya irkı koyunlarda yapılan linear meme puanlamasinda ayrılma derecesi 6.74, Gelasakis ve ark. (2012) Sakız ırkı koyunlarla yaptığı çalışmada 3.83 ve Koyuncu ve Altınçekiç (2011) Tahirova, Kıvırcık ve Karacabey Merinosun bu değerleri sırasıyla; 3.42 , 3.74 ve 3.43 olarak bulmuşlardır. Koyunlarda ayrılma derecesi düşük olan memelerde sarkmalar, laktasyonun ilerleyen dönemlerinde veya ilerleyen doğumlarda ortaya çıkabilir. Bu durum dikkate alınarak sütçü koyunlarda seleksiyon uygulamasinın gerçekleştirilmesi gerekir. Aksi takdirde laktasyon veya yaş ile birlikte memedeki sarkmalardan dolayı meme sağlığı ile ilgili problemlerin ortaya çıkması kaçınılmazdır bu da sürüde ayıklama hızını artıracaktır.

Kıvırcık koyunlarında meme bağlantı derecesi puanı ortalaması 6.9 olarak bulunmuştur. Fernando de la Fuente ve San Primitivo (1996) Churra rrkı koyunlarda bu değeri 5.14; Koyuncu ve Altınçekiç (2011) Tahirova, Kıvircık ve Karacabey Merinosu rrklarında ise $8.22, \quad 7.23$ ve 7.65 olarak tespit etmişlerdir. Özellikle memenin alt karın bölgesine yapmış olduğu bağlanma açısı hayvanların laktasyon dönemlerinin uzun ya da kısa olmasını etkilemektedir. Bağlantısı zayıf olan memeler üçüncü veya dördüncü laktasyondan sonra aşırı derecede sarkmakta, bu tip memeye sahip koyunlar her türlü etkene açık hale gelmektedir (Şahin 2011; Koyuncu ve Altınçekiç 2016).

Koyunlarda memesi büyük olanların süt veriminin daha yüksek olduğu (Labussiere ve ark. 1981), günlük ve laktasyon süt verimleri ile meme çevresi (Mundan ve Özbeyaz 2004), meme hacmi, meme başları arası mesafe, meme genişliği, uzunluğu ve derinliği arasında (Labussiere ve ark. 1981) pozitif korelasyon olduğu ifade edilmektedir. Kızılay (1983) tarafindan yapılan bir araştırmada, meme yüksekliği, genişliği, derinliği ve çevresi ile süt verimi arasında yüksek düzeyde pozitif korelasyonlar olduğu $(\mathrm{P}<0.05 ; \mathrm{P}<0.01)$, meme başlarına ait fenotipik özellikler söz konusu olduğunda ise korelasyonların negatif ve düşük düzeylerde kaldığı bildirilmiştir.

Koyunlarda MBU-MBY, MBU-AD arasinda negatif yönde bir korelasyon bulunmaktadır $(\mathrm{P}<0.05)$. Bu durumda MBY ve AD azaldıkça, MBU'nun arttığı söylenebilir. Araştırma esnasında yapılan gözlemlerde MBY ve AD laktasyonun sonuna doğru azaldığı buna karşın MBU'nun arttığı belirlenmiştir. Diğer taraftan MBD-MU, MBD-IMAU ve MB-MBG arasinda pozitif yönlü bir korelasyon söz konusudur $(\mathrm{P}<0.05)$. Morfolojik meme özellikleri arasında (MC-MY, MCMU, MC-IMAU, MC-MBG, MY-MU, MY-İMAU, MYMBG, MY-MBU, MU-IMAU, MU-MBG, IMAU-MBG) yüksek ve pozitif yönlü korelasyonlar bulunmaktadır $(\mathrm{P}<0.01) . \mathrm{Bu}$ da özelliklerden birinin diğeriyle ayn yönde artacağı ya da azalacağını ifade etmektedir (Çizelge 5).

Koyuncu ve Altınçekiç (2011), üç farklı ırkta yaptıkları çalışmada linear meme özelliklerinden meme bağlantı derecesi ile meme derinliği arasındaki fenotik korelasyonu Tahirova koyunu için $(0.714)$, $(\mathrm{P}<0.01)$; Kıvırcık koyunu için 0.357 ve Karacabey Merinos koyunu için 0.343, $(\mathrm{P}<0.05)$ olarak bulmuşlardır. Özellikle yüksek puanlı meme bağlantı derecesine 
sahip hayvanlardan daha fazla süt elde edildiği ve damızlık seçiminde bu özelliklerin göz önünde bulundurulması gerektiği belirtilmektedir. Memenin sarkık yapıda olması askı ligamentlerinin gevşemesi sonucu meme başlarının yere yakın olması sonucunu doğurmakta bu durumdaki koyunlarda sağım ve kuzular tarafindan emilmede problemler çıkarabilmektedir. Emediato ve ark. (2008) meme ölçüleri ile süt verimi arasındaki korelasyonun ancak yavrular sütten kesildikten sonra yüksek düzeyde ve pozitif yönde seyrettiğini, öncesinde hayvanların memelerinin sütle dolu olmasına rağmen içgüdüsel olarak sütlerini yavrularına ayırıp vermediklerini bu nedenle strese girdiklerini ve dolayısıla da meme ölçüleri ile süt verimi arasındaki korelasyonların düşük ve negatif çıktığını bildirmişlerdir.

Çizelge 5. Morfolojik meme özellikleri ve linear meme değerlendirilmesi arasındaki korelasyonlara

Table 5. Correlations between morphological udder caharacteristics and linear udder evaluationa

\begin{tabular}{|c|c|c|c|c|c|c|c|c|c|}
\hline & $\begin{array}{l}\text { MBY } \\
(T P)\end{array}$ & $\begin{array}{l}\mathrm{MD} \\
(U D)\end{array}$ & $\begin{array}{l}\text { MBD } \\
(D S U)\end{array}$ & $\begin{array}{l}\mathrm{AD} \\
(D S E)\end{array}$ & $\begin{array}{l}\mathrm{MÇ} \\
(U D)\end{array}$ & $\begin{array}{l}\mathrm{MY} \\
(U H)\end{array}$ & $\begin{array}{l}\mathrm{MU} \\
(U L)\end{array}$ & $\begin{array}{l}\text { İMAU } \\
(T D)\end{array}$ & $\begin{array}{l}\text { MBG } \\
(T W)^{2}\end{array}$ \\
\hline $\mathrm{MD}(U D)$ & -0.06 & & & & & & & & \\
\hline $\operatorname{MBD}(D S U)$ & -0.22 & -0.14 & & & & & & & \\
\hline $\mathrm{AD}(D S E)$ & 0.11 & -0.28 & -0.03 & & & & & & \\
\hline $\mathrm{MÇ}(U D)$ & -0.12 & -0.02 & 0.31 & 0.10 & & & & & \\
\hline MY (UH) & -0.29 & 0.07 & 0.30 & -0.03 & $0.56^{* *}$ & & & & \\
\hline $\mathrm{MU}(U L)$ & -0.24 & -0.05 & $0.36^{*}$ & 0.03 & $0.71^{* *}$ & $0.84^{* *}$ & & & \\
\hline İMAU $(T D)$ & -0.15 & 0.02 & $0.37^{*}$ & -0.15 & $0.65^{* *}$ & $0.48^{* *}$ & $0.52^{* *}$ & & \\
\hline $\mathrm{MBG}(T W)$ & -0.39 & 0.18 & $0.33^{*}$ & -0.20 & $0.45^{* *}$ & $0.45^{* *}$ & $0.47^{* *}$ & $0.50^{* *}$ & \\
\hline $\operatorname{MBU}(T L)$ & $-0.38^{*}$ & 0.28 & 0.26 & $-0.37^{*}$ & 0.26 & $0.52^{* *}$ & $0.41^{*}$ & $0.41^{*}$ & $0.83^{* *}$ \\
\hline
\end{tabular}

${ }^{*} \mathrm{P}<0.05,{ }^{* *} \mathrm{P}<0.01$, a: 9 dönemin ortalamasi,

MBY/TP. Meme başı yerleşimi/Teat placement, MD/UD: Meme derinliği/Udder depth, AD/DSE. İki yarının ayrılma derecesi/Degree of seperation, MBD/DSU: Meme bağlantı derecesi/Degree of suspension, MÇ/UD: Meme çevresi/Udder circumference, MY/UH: Meme yüksekliği/Udder height, MU/UL: Meme uzunluğu/Udder length, İMAU/TD: İki meme başı arası uzaklık/Teat distance, MBG/TW: Meme başı genişliği/Teat width, MBU/TL: Meme başı uzunluğu/Teat length.

Memeye ait morfolojik özelliklerin kendi aralarındaki fenotipik korelasyonlar linear meme özelliklerinden farklı olarak ağırlıklı olarak pozitif ve önemli bulunmuştur. Sarı ve ark. (2015), Tuj koyununda meme özelliklerinin kendi aralarında yüksek korelasyona sahip olduklarını ve bunun 0.32 ile 0.68 arasında değiştiğini, özellikle meme genişliği ile meme çevresi ve meme derinliği arasındaki korelasyon katsayılarını 0.68 ve 0.54 olarak bildirmişlerdir. Benzer şekilde Tahirova, Kıvırcık ve Karacabey Merinosu koyunlarında meme morfolojik özellikleri ile linear özellikler arasında pozitif ve önemli ilişkiler saptanmıştır (Koyuncu ve Altınçekiç 2011).

\section{SONUÇ ve ÖNERİLER}

$\mathrm{Bu}$ çalışmada yetiştirici koşullarında Kıvırcık koyunlarında meme ölçüleri ve linear meme skorlaması yapılmıştır. Çalışmanın yetiştirici koşullarındaki mevcut durumu ortaya koyması açısından ayrı bir önemi bulunmaktadır. Doğrusal skor, meme morfolojisini olabildiğince kesin olarak karakterize etmelidir, ancak sistemin çok karmaşık olmaması ve uygulamada çok zaman alıcı olmaması için sınırlı ölçek ve sayıda kriter kullanılması gerekir. Meme morfolojisinin bireysel özellikleri arasındaki ilişkilerin bilgisi, bunların toplam seçim indekslerine dahil edilmesi veya meme morfolojisi için kısmi seçim indekslerinin oluşturulması için de önemlidir ve süte yönelik seçim şemalarında gelecekteki ilişkili yanıtları tahmin etmeyi mümkün kılar. Seçim indeksi yapısı için özellikler arasındaki genetik korelasyonlara ihtiyaç vardır, ancak genetik korelasyonların makul tahmini büyük ve iyi yapılandırılmış veriler gerektirir. Araştırmada ele alınan meme özellikleri ve meme şeklinin özellikle meraya dayalı süt koyunu yetiştiriciliği yapan işletmeler açısından önemli bir seleksiyon kriteri olarak kullanılabileceğini, ayrıca meme özelliklerinin sağım performansı ve verimle ilgisi olduğu gösteren korelasyon değerleri elde edilmiştir.

\section{TEŞEKKÜR}

Bu makale Hilal Akgün'ün yüksek lisans tezinin bir bölümünden hazırlanmış olup, araştırmayı destekleyen Bursa Uludağ Üniversitesi Bilimsel Araştırma Projeleri Komisyonuna (HDP(Z) 2017/4) teşekkür ederiz.

\section{Araştırmacıların Katkı Oranı Beyan Özeti}

Yazarlar makaleye eşit oranda katkı sağlamış olduklarını beyan eder.

\section{Çıkar Çatışması Beyanı}

Makale yazarları aralarında herhangi bir çıkar çatışması olmadığını beyan ederler. 


\section{KAYNAKLAR}

Ayadi M, Such X, Ezzehizi N, Zouari M, Najar T, M' Rad, MB, Casals R 2011. Relationship Between Mammary Morphology Traits and Milk Yield of Sicilo-Sarde Dairy Sheep in Tunisia. Small Ruminant Research, 96: 41-45.

Banchero GE, Quintans G, Martin GB, Lindsay DR, Milton JTB 2004. Nutrition And Colostrum Production in Sheep. 1. Metabolic And Hormonal Responses To A High-Energy Supplement İn The Final Stages Of Pregnancy. Reproduction, Fertility and Development, 16:1-11.

Butler WRSM, Cappiello LA, Handwerger S 1981. The Relationship Between Breed and Litter Size in Sheep And Maternal Serum Concentrations Of Placental Lactogen, Estradiol And Progesterone. Journal of Animal Science, 53:1077-1081.

Casu S, Pernazza I, Carta, A 2006. Feasibility Of A Linear Scoring Method of Udder Morphology For The Selection Scheme Of Sardinian Sheep. Journal of Dairy Science, 89: 2200-2209.

Casu S, Sech S, Salaris SL, Carta A 2010. Phenotypic and Genetic Relationships Between Udder Morphology And Udder Health In Dairy Ewes. Small Ruminant Research, 88: 77-83.

De la Fuente LF, Fernandez G, San Primitivo F 1996. A Linear Evaluation System For Udder Traits of Dairy Ewes. Livestock Production Science, 45, 171178.

Doğan Ş, Aytekin İ, Boztepe S 2013. Anadolu Merinosu Koyunlarında Meme Tipleri İle Meme Özellikleri, Süt Verimi Ve Bileşenleri Arasındaki İlişkiler. Tekirdağ Ziraat Fakültesi Dergisi, 10 (2): 58-69.

Emediato RMS, Siqueira ER, Stradiotto MM, Maest'a SA, Fernandes S 2008. Relationship Between Udder Measurements and Milk Yield in Bergamasca Ewes in Brazil. Small Ruminant Research, 75: 232-235.

Epstein H 1985. The Awassi Sheep With Special Reference To The Improved Dairy Type. FAO Animal Production and Health Paper 57, Food and Agriculture Organization of The United Nations. Rome.

Fernandez G, Alvarez P, San Primitivo F, De la Fuente LF 1995. Factors Affecting Variation of Udder Traits of Dairy Ewes. Jornal of Dairy Science, 78, 342-849.

Fernando de la Fuente LG, San Primitivo F 1996. A Linear Evaluation System for Udder Traits of Dairy Ewes. Livestock Production Science, 45: 171-178.

Gallego L, Caja G, Torres A 1983. Estudio De La Tipología Y Características Morfológicas De Las Ubres De Ovejas De Raza Manchega Desde El Parto. In: 3rd International Symposium on Machine Milking of Small Ruminants. Sever-Cuesta, Valladolid, Spain. pp. 100-116.

Gelasakis AI, Arsenos G, Valergakis GE, Oikonomou G, Kiossis E, Fthenakis GC 2012. Study of Factors
Affecting Udder Traits and Assessment of Their Interrelationships With Milking Efficiency in Chios Breed Ewes. Small Ruminant Research, 103:232_ 239.

Iniguez L, Hilali M, Thomas DL, Jesry G 2009. Udder Measurements and Milk Production in Two Awassi Sheep Genotypes and Their Crosses. Jornal of Dairy Science, 92:4613-4620.

Izadifard J, Zamiri MJ 1997. Lactation Performance of Two Iranian Fat-Tailed Sheep Breeds. Small Ruminant Research, 24: 69-76.

Kızılay E 1983. Beyaz Alman x Malta $\left(\mathrm{F}_{1}\right)$ Keçilerinde Meme Özellikleri ve Süt Verimleriyle İlişkileri. Ege Üniversitesi Ziraat Fakültesi Yayınları, No: 461.

Koyuncu M, Öziş Altınçekiç Ş 2011. Kıvırcık, Tahirova ve Karacabey Merinosu Irkı Koyunlarda Linear Meme Özellikleri, Meme Ölçüleri Ve Süt Verimi Arasındaki İlişkiler. 7. Ulusal Zootekni Bilim Kongresi, 14-16 Eylül 2011. Adana.

Koyuncu M, Öziş Altınçekiç Ş 2016. Saanen X Kıl Melez Keçilerinde Linear Meme Özellikleri ve Somatik Hücre Sayısı Arasındaki İlişkiler. Gaziosmanpaşa Üniversitesi Ziraat Fakültesi Dergisi, 33 (3): 148-156.

Kumlu S 1999. Damızlık ve Kasaplık Sığır Yetiştirme. Setma Matbaacılık, Ankara, 166 sy.

Labussiere J, Dotchewski D, Combaud JF 1981. Caracteristiques Morphologiques De La Mamelle Des Brebis Lacaune. Methodologie Pour L'optention Des Donnees. Relations avec l'aptitude a la traite. Ann. Zootech., 30: 115-136.

Legarra A, Ugarte E. 2005 Genetic Parameters of Udder Traits, Somatic Cell Score, and Milk Yield in Latxa Sheep. Jornal of Dairy Science, 88:22382245.

Legaz E, Cervantes I, Pérez-Cabal MA, Fernando de la Fuente L, Mártinez R, Goyachee F, Gutiérrez JP 2011. Multivariate Characterisation of Morphological Traits in Assaf (Assaf.E) Sheep. Small Ruminant Research, 100: 122- 130.

Makovický P, Nagy M, Makovický P 2013. Comparison of External Udder Measurements of The Sheep Breeds Improved Valachian, Tsigai, Lacaune And Their Crosses. Chilean Journal of Agricultural Research, 73(4) October-December.

Margetín M, Oravcová M, Apolen D, Milerski M 2012. Genetic Parameters for Udder Traits in Slovak Dairy Sheep and Their Crosses With Specialized Breeds. Journal of Life Sciences, 6: 1363-1370.

Marie-Etancelin C, Astruc JM, Porte D, Larroque H, Robert-Granie C 2005. Multiple-Trait Genetic Parameters And Genetic Evaluation of Udder-Type Traits in Lacaune Dairy Ewes. Livestock Production Science, 97: 211-218.

Martínez ME, Calderón C, Barra RD, Fernando de la Fuente L, Gonzalo C 2011. Udder Morphological Traits and Milk Yield of Chilota and Suffolk Down Sheep Breeds. Chilean Journal of Agricultural 
Research, 71(1):90-95.

Mavrogenis AP, Papachristoforou C, Lysandrides P, Roushias A 1989. Environmental and Genetic Effects of Udder Characteristics and Milk Production in Damascus Goats. Small Ruminant Research, 2(4): 333-343.

Minitab Inc. 2014. MINITAB release 17: statistical software for windows. Minitab Inc, USA.

Mundan D, Özbeyaz C 2004. Akkaraman, Kıvırcık X Akkaraman $G_{1}$ ve Sakı $X$ Akkaraman $G_{1}$ Koyunlarda Süt Verim Özellikleri İle Kuzularda Büyüme ve Yaşama Gücü. Lalahan Hayvancılık. Araştırma Enstitüsü Dergisi, 44(2): 23-35.

Özyürek S, Türkyılmaz D, Yaprak M, Esenbuga N 2016. Determination of Morphological and Linear Udder Traits in Morkaraman, Tuj and Awassi Sheep. Indian Journal of Animal Research, 52 (3): 424-430.

Prpıć Z, Mıoč B, Vnučec I, Vrdoljak J, Pavić V 2012. Morphology of Wheat and Milk Fat of Goat's Sheep. 47th Croatian and 7th International Symposium on Agriculture. February $13-17,2012$. Opatija, Croatia.

Sadeghi S, Rafat A, Bohlouli M 2014. Effect of Crossbreeding on Linear Udder Scores and Their Phenotypic Relationships in İranian Fat-Tailed Ewe's. Biotechnology in Animal Husbandry, 30 (1): 61-77.

Salaris S, Casu S, Carta A 2014. Investigating The Relationship Between The Prion Protein Locus and Udder Morphology Traits and Milk Yield in Sardinian sheep. Jornal of Animal Science, 2007. 85:2840-2845.

Sarı M, Yılmaz İ, Önk K 2015. Effects of Lactation Stage, Lactation Order and Udder Types on Udder Traits and Composition of Milk in Tuj Ewes. Ankara Üniversitesi Veteriner Fakültesi Dergisi, 62: 313-318.

Schoknecht PA, Nobrega SN, Petterson JA, Ehrhardt RA, Slepetis R, Bell AW 1991. Relations Between
Maternal and Fetal Plasma Concentrations of Placental Lactogen and Placental and Fetal Weights in Well-Fed Ewes. Journal of Animal Science, 69:1059-1063.

Serranoa M, Pe'rez-Guzma MD, Montoro V, Jurado JJ 2002. Genetic analysis of udder traits in Manchega ewes. Livestock Production Science, 77: 355-361.

Sezenler T, Ceyhan A, Yüksel MA, Önaldı AT, Yıldırır M 2016. Effect of Parity and Type of Lambing on Performance and Udder Traits of Bandirma Ewes. Indian Journal of Animal Science, 86 (5): 572-577.

Şahin O 2011. Süt Sığırlarında Tip Sinıflandırması Ve Vücut Kondisyonu Değerlendirme. TDSYMB Yayınları, Akyazı Matbaası, Ankara, 112 sy.

Şeker I, Kul S, Bayraktar M 2000. İvesi ve Ost-Friz X İvesi Melezi $\left(\mathrm{F}_{1}\right)$ Koyunlarda Linear Meme Özellikleri ve Bunlar ile Süt Verimi Arasındaki İlişkiler. Lalahan Hayvancılık Araştırma Enstitüsü Dergisi, 40 (2): 45-55.

Thomas DL, Berger YM, McKusick BC, Gottfredson RG 2000. Comparison of East Friesian-Crossbred and Lacaune-Crossbred Ewe Lambs for Dairy Sheep Production. Proceedings of the 6th Great Lakes, Dairy Sheep Symposium, November 2-4, 2000, Guelph, Ontario, Canada.

Trimberger GW, Etgen M, Galton DM 1992. Dairy Cattle Judging Techniques. Fourth Edition, Waveland Press, Inc. Prospect Heights, Illinois, U. S. A. 350 sy.

Uzmay C, Kaya İ, Akbaş Y, Kaya A 2003. Siyah Alaca İneklerde Meme ve Meme Başı Formu ile Laktasyon Sirası ve Laktasyon Döneminin Subklinik Mastitis Üzerine Etkisi. Turkish Journal of Veterinary and Animal Sciences, 27: 695-701.

Yardımcı M, Özbeyaz C 2001. Akkaraman, Sakız X Akkaraman Melezi $F_{1}$ Koyunlarının Süt Verimi ve Meme Özelliklerinin Karşılaştırılması. Lalahan Hayvancılık Araştırma Enstitüsü Dergisi, 41(2): 63 -77 . 